\section{Vértebra coccígea como alternativa a autoenxertia óssea tradicional - avaliação tomográfica e biomecânica em cães ex vivo}

\author{
Coccygeal vertebra as an alternative to traditional autograft \\ bone - tomography and biomechanical study in ex vivo dogs
}

Gabriele Maria Callegaro Serafini*, Ney Luis Pippi², Roberta do Nascimento Libardoni³, Renato do Nascimento Libardoni4 ${ }^{4}$, Daniel Curvello de Mendonça Müller ${ }^{5}$, Bruna Portolan Amaral ${ }^{6}$, Igor Giacomelli Zanella7 \& Carlos Roberto Cauduro ${ }^{8}$

'Médica veterinária, Dra., Docente. Departamento de Estudos Agrários, Universidade Regional do Noroeste do Estado do Rio Grande do Sul - UNIJUÍ, ljuí, RS, Brasil

2Médico veterinário, Dr. Laboratório de Cirurgia Experimental, Universidade Federal de Santa Maria - UFSM, Santa Maria, RS, Brasil

${ }^{3}$ Graduanda. Medicina Veterinária, Centro de Ciência Agrárias, Universidade Federal de Santa Maria - UFSM, Santa Maria, RS, Brasil

${ }^{4}$ Médico veterinário, MSc, Residente. Programa de Residência Integrada em Medicina Veterinária, Universidade de Passo Fundo - UPF, Passo Fundo, RS, Brasil

${ }^{5}$ Médico veterinário, Dr, Docente. Departamento de Clínica de Pequenos Animais, Universidade Federal de Santa Maria - UFSM, Santa Maria, RS, Brasil

${ }^{6}$ Médica veterinária, Doutoranda. Programa de Pós-graduação em Medicina Veterinária, Universidade Federal de Santa Maria - UFSM, Santa Maria, RS, Brasil

TTecnólogo em Fabricação Mecânica, Mestrando. Programa de Pós-graduação em Engenharia Mecânica, Universidade Federal do Paraná - UFPR, Curitiba, PR, Brasil

${ }^{8}$ Engenheiro Mecânico, Docente. Departamento de Engenharia Mecânica, Universidade Federal de Santa Maria - UFSM, Santa Maria, RS, Brasil

\section{Resumo}

A enxertia óssea é um recurso muito utilizado pelo ortopedista veterinário para reconstrução de membros acometidos por perda total de segmento ósseo cortical. Entretanto, a ausência de banco de ossos e a presença de autoenxertos com dimensões estruturais insuficientes são contratempos temidos na escolha deste recurso. Devido a isso, este trabalho teve como objetivo investigar as características estruturais da vértebra coccígea sugerindo-a como possível alternativa para autoenxertia óssea. Para tal, foram utilizados oito cães ex vivos, sendo cada cão doador de duas amostras de cada um dos seguintes grupos de enxertos ósseos: porção crânio-dorsal da asa do ílio direita e esquerda (grupo A), fragmento da 10ª costela direita e esquerda (grupo C), 4a e 5a vértebras coccígeas (grupo Co) e porção diafisária da tíbia direita e esquerda (grupo T), resultando em 16 amostras por grupo. Tais enxertos foram submetidos a exame de tomografia computadorizada para mensuração de osso esponjoso e osso cortical e teste biomecânico para avaliação da resistência. A vértebra coccígea ofereceu boa resistência óssea e apresentou elevado percentual de osso esponjoso, conferindo a ela, além de provável alto poder osteogênico, também de suporte estrutural.

Palavras-chave: ortopedia, falha óssea, enxerto corticoesponjoso.

\begin{abstract}
Bone grafting is a resource widely used by the veterinary orthopedic surgeon for reconstruction of affected limbs for a total loss of a cortical bone segment. However, the absence of bone bank and the presence of autografts with insufficient structural dimensions are feared setbacks in choosing this resource. Because of this, this study aimed to investigate the structural characteristics of coccygeal vertebra suggesting it as a possible alternative to bone autograft. For this, were used eight, ex vivos, dogs, with each dog donor of two samples of each bone grafts following groups: cranial-dorsal portion of the right and left iliac crest (group A), $10^{\text {th }}$ fragment of the right and left ribs (group C), $4^{\text {th }}$ and $5^{\text {th }}$ coccygeal vertebrae (group Co) and diaphyseal portion of the right and left tibia (group T), resulting in 16 samples per group. Such grafts underwent computed tomography for measurement of cancellous bone and cortical bone and biomechanical test to evaluate the resistance. The coccygeal vertebra offered good bone strength and showed a high percentage of cancellous bone, conferring to it, in addition to probable large power osteogenic also structural support.
\end{abstract}

Keywords: orthopedics, bone loss, corticocancellous graft. \section{BJ M

Como citar: Serafini, G. M. C., Pippi, N. L., Libardoni, R. N., Libardoni, R. N., Müller, D. C. M., Amaral, B. P. Zanella, I. G., \& Cauduro, C. R. (2017). Vértebra coccígea como alternativa a autoenxertia óssea tradicional - avaliação tomográfica e biomecânica em cães ex vivo. Brazilian Journal of Veterinary Medicine, 39(1), 54-60. doi: 10.29374/2527-2179. bjvm027817

Fonte de financiamento: Nenhuma.

Conflito de interesses: Os autores declaram não haver conflito de interesses que precisam ser informados.

Recebido: Fevereiro 09, 2016 Aceito: Novembro 14, 2016

O estudo foi realizado na Universidade Federal de Santa Maria - UFSM, Santa Maria, RS, Brasil.

\section{*Correspondência}

Gabriele Maria Callegaro Serafini Departamento de Estudos Agrários, Universidade Regional do Noroeste do Estado do Rio Grande do Sul - UNIJUÍ

Rua do Comércio, 3000

CEP 98700-000 - ljuí (RS), Brasil

E-mail: gabrieleserafini@yahoo.com.br

Copyright Serafini et al. Este é um artigo publicado em acesso aberto (Open Access) sob a licença Creative Commons Attribution Non-Commercial, que permite uso, distribuição e reprodução em qualque meio, sem restrições desde que sem fins comerciais e que o trabalho original seja corretamente citado. 


\section{Introdução}

O uso de enxertos ósseos é um procedimento bem sedimentado na ortopedia veterinária (Denny \& Butterworth, 2006), tanto pelos seus benefícios na cicatrização como na preservação de membros. Em função disso, eles são recomendados para várias adversidades ortopédicas, como não-uniões, uniões retardadas, falhas corticais e fraturas com perda de segmento ósseo total (Serafini et al., 2016).

Um enxerto ósseo ideal oferece células osteogênicas que produzem osso novo, além de fatores osteoindutores, que induzem as células mesenquimais indiferenciadas a se diferenciarem em células ósseas. Oferece ainda, uma matriz osteocondutora, a qual atua como estrutura para o crescimento interno de osso novo e suporte mecânico para a estrutura óssea. Dependendo do tipo de enxerto, ele pode realizar uma ou mais funções, sendo que a escolha por um ou outro vai depender das funções requeridas (Millis \& Martinez, 2007).

Os enxertos corticoesponjosos são considerados o "padrão ouro" da enxertia óssea (Gomes, 2008), pois quando implantados no hospedeiro, apresentam ação osteogênica, osteocondutiva e osteoindutiva (Bauer \& Muschler, 2000), além de suporte estrutural (Denny \& Butterworth, 2006). As costelas e a porção craniodorsal da asa do ílio são os locais doadores mais comuns, podendo ser utilizados como autoenxertos a fresco ou como aloenxertos conservados (Piermattei Filho \& Decamp, 2009).

Os enxertos costais podem ser utilizados no reparo das fraturas fragmentares e na substituição de defeitos segmentares, sendo a nona costela e a décima costela as mais fáceis de coletar em decorrência da pouca musculatura subjacente (Stevenson, 1996). Devido a sua anatomia curva, as costelas oferecem a vantagem de serem utilizadas em falhas de sínfise mandibular, entretanto, sua coleta acarreta em risco de lesão pleural e possíveis complicações no tratamento pós-operatório dessa lesão (Gomes, 2008).

A asa do ílio pode ser utilizada em forma de lascas no interior das articulações para auxiliar na estabilização em artrodeses, assim como em forma de bloco para preenchimento de defeitos corticais. O enxerto é esculpido para que se encaixe no defeito e deve-se fixá-lo rigidamente com parafusos de revestimento ou cerclagens (Stevenson, 1996).

Tanto a asa do ílio como a costela apresentam características compatíveis com a de um enxerto ósseo corticoesponjoso, entretanto devido ao formato curvado de ambas, não se recomenda suas aplicações em sítios receptores que suportem peso (Yeh et al., 1991). Diante disso, despertou-se o interesse pela realização deste estudo, o qual tem por objetivo avaliar a resistência e características estruturais da vértebra coccígea, partindo-se da suposição de que ela é de fácil obtenção, apresenta as características esperadas em um enxerto ósseo ideal e possui formato e diâmetro adequado para ser aplicada em defeitos ósseos de segmento total.

\section{Material e métodos}

Essa pesquisa foi aprovada pelo CEUA/UFSM, sob parecer 097/2014. Para tal, foram obtidos do setor de Patologia Veterinária da instituição (UFSM), oito cães adultos, ex vivos, de ambos os sexos, de diferentes raças, com massa corporal média de 7,5 kg ( $\pm 2,02$ quilogramas) e idade média de 9,00 anos ( $\pm 3,87$ anos) e livres de doenças ou alterações ósseas. De cada cão coletou-se a porção diafisária da tíbia direita e esquerda (grupo T), porção crânio-dorsal da asa do ílio direita e esquerda (grupo A), 4a e 5a vértebras coccígeas (grupo Co) e porção do terço proximal da 10a costela direita e esquerda (grupo C) (Figura 1). Com isso, cada grupo foi composto por 16 amostras.

Foram removidos os tecidos moles e periósteo de todos os segmentos ósseos (enxertos), sendo que nas vértebras coccígeas, as apófises e o arco dorsal também foram seccionados, assim como os discos intervertebrais curetados, permanecendo o corpo da vértebra. De acordo com o comprimento da 4 a vértebra coccígea de cada cão, foi determinado o mesmo comprimento dos outros segmentos ósseos do mesmo animal, a fim de que cada cão fornecesse sempre comprimentos iguais de cada segmento.

Nos segmentos das costelas, realizaram-se dois cortes transversais na região do terço proximal. Na asa do ílio, realizaram-se dois cortes dorsoventrais (um próximo à articulação sacro-ilíaca e outro mais cranial) e um corte ventral, no sentido craniocaudal, imediatamente abaixo da região mais espessa dessa porção, mimetizando o mesmo local de secção que se utilizaria esse 


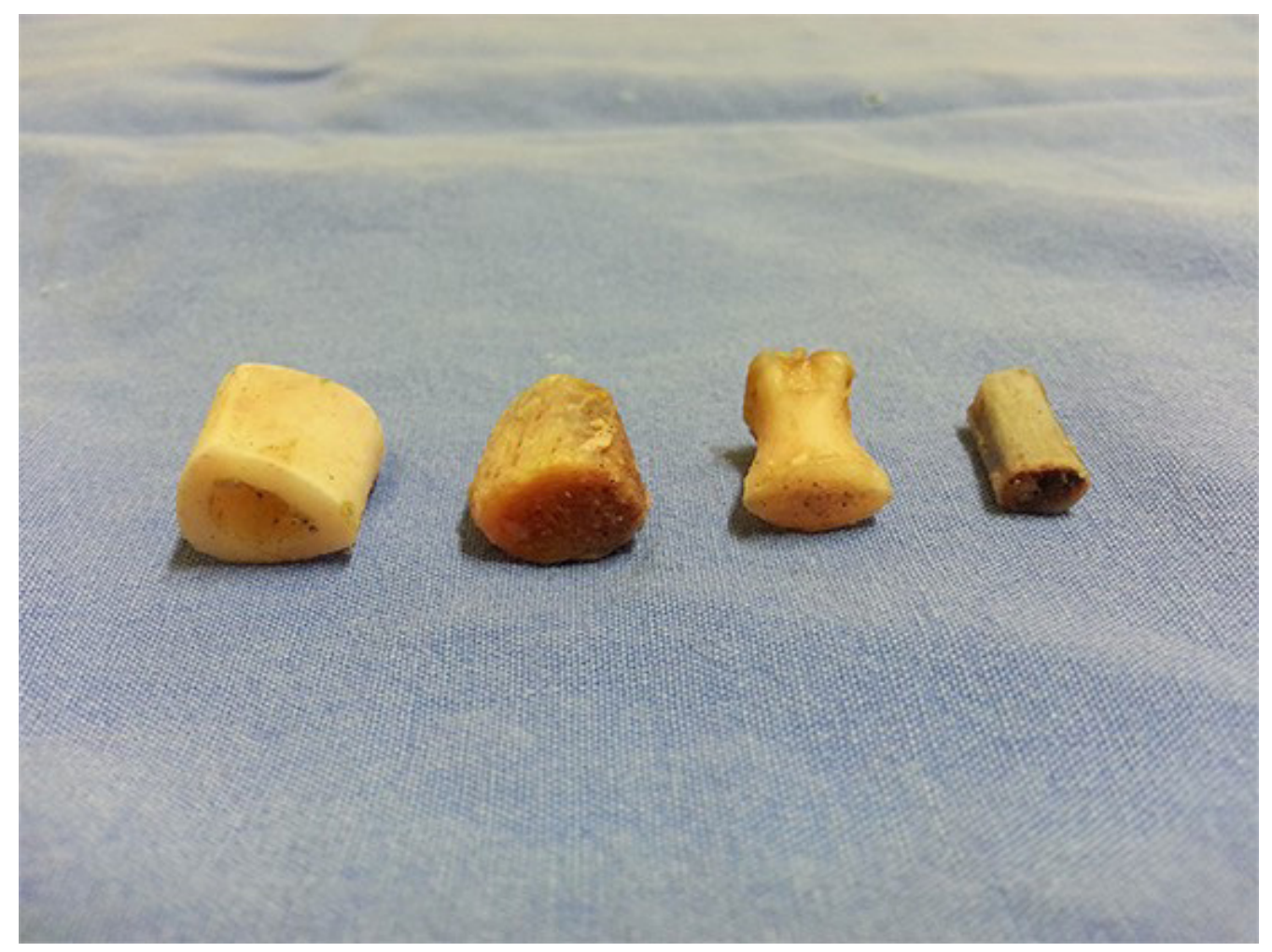

Figura 1. Enxertos da tíbia, asa do ílio, vértebra coccígea e costela, respectivamente.

enxerto na rotina. Na tíbia, mensurou-se o comprimento da mesma e a partir do seu ponto médio realizaram-se dois cortes transversais resultando em um segmento ósseo da região diafisária. Por fim, as extremidades da $5^{a}$ coccígea foram seccionadas para deixar no mesmo comprimento da 4a. Posteriormente, os enxertos foram lavados em solução de $\mathrm{NaCl} \mathrm{0,9 \%} \mathrm{para} \mathrm{remoção} \mathrm{de}$ pequenas sujidades, colocados em sacos plásticos vedados e congelados em freezer a $-80^{\circ} \mathrm{C}$.

Após a obtenção do número suficiente de amostras, os enxertos ósseos foram transportados em caixa térmica para realização de tomografia computadorizada (Figura 2A) com cortes axiais de 0,625 mm de espessura e posteriormente devolvidos ao freezer até a realização dos ensaios biomecânicos.

A tomografia computadorizada teve por objetivo permitir a mensuração da proporção de osso esponjoso e osso cortical de cada enxerto. As imagens foram registradas no computador e processadas em uma estação de trabalho. A partir desse exame de imagem, obtiveram-se várias secções transversais de cada segmento ósseo, onde em cada secção foi possível observar um contorno composto por osso cortical; e um centro, composto por osso esponjoso (Figura 2B). Como a figura geométrica que melhor se assemelha a essas secções é o círculo, obteve-se a área total desse círculo e posteriormente a área central (correspondente a área de osso esponjoso). Por fim, ao subtrair-se a área total da área de osso esponjoso, obteve-se a área de osso cortical (correspondente a área de uma coroa circular em termos matemáticos).

Para a obtenção do valor do raio a ser empregado na fórmula da área, somou-se o valor da espessura de osso cortical com a metade do valor da espessura do osso esponjoso. Com o objetivo de diluir erro, mensurou-se a espessura de osso cortical em quatro pontos diferentes e dividiu-se por quatro para obter a média. Já, a espessura do osso esponjoso foi mensurada em duas direções diferentes e dividida por dois (Figura 2C). Com isso, o cálculo da média das espessuras de cada osso permitiu transformar o formato quase circular das secções desses ossos em um círculo perfeito, com área extremamente próxima ao formato original.

Além disso, sabendo-se que os segmentos ósseos não apresentam forma regular ao longo de todo o seu comprimento, em cada segmento ósseo realizou-se a área de três secções diferentes (duas delas mais próximas às extremidades e uma mais central) e suas médias aritméticas 


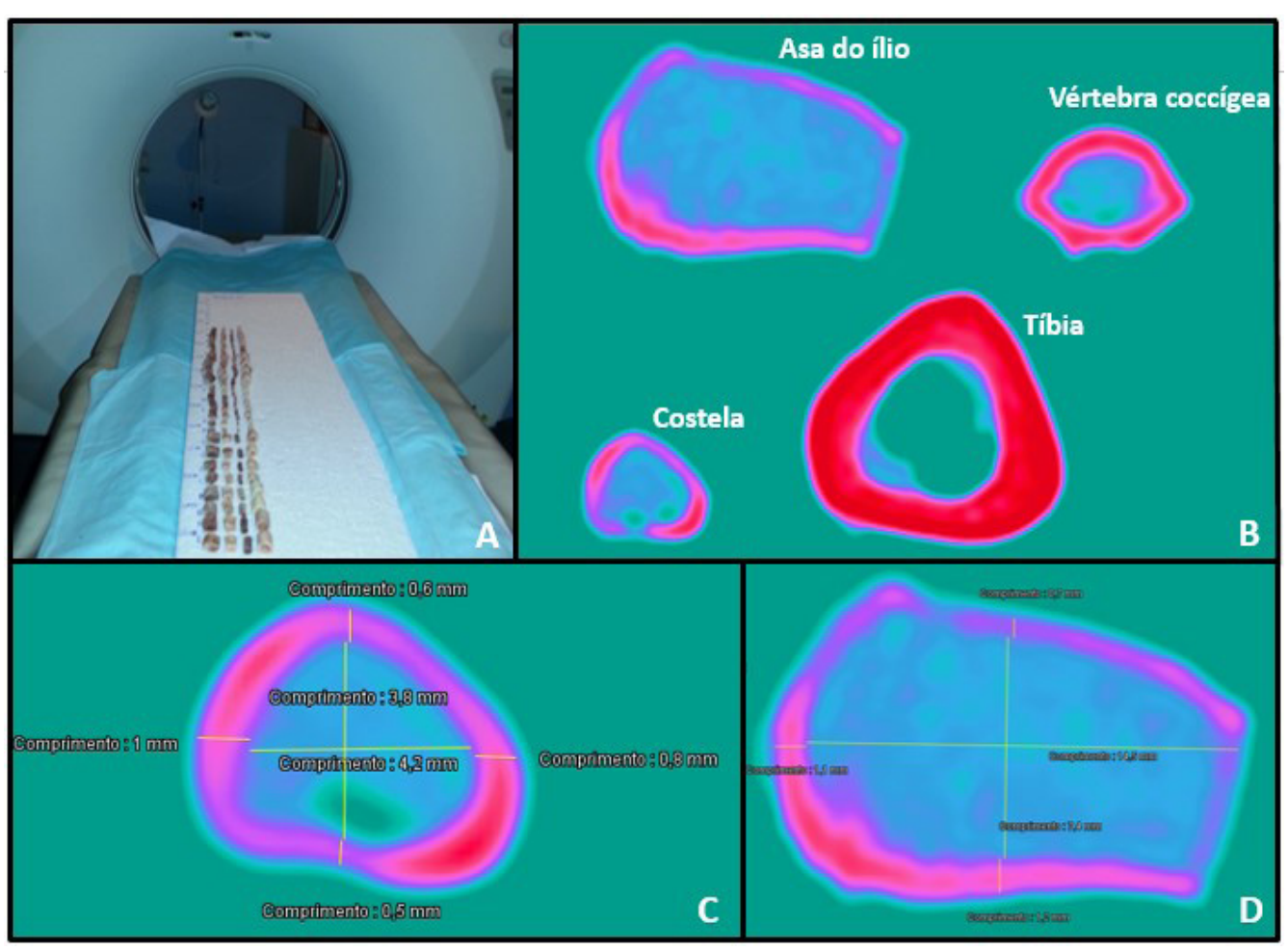

Figura 2. A - Segmentos ósseos posicionados para exame de tomografia computadorizada. B- Secção transversal de cada segmento ósseo. Observar contorno em tom rosa demonstrando a espessura do osso cortical; e em tom azulado a de osso esponjoso (exceto na tíbia). C - Demonstração da mensuração da espessura de osso cortical em quatro pontos distintos e de osso esponjoso em duas direções. D - Asa do ílio apresentando-se com aproximadamente 75\% da área de uma coroa circular, correspondente a área de osso cortical.

foram obtidas. Diante dos valores das áreas de osso esponjoso e osso cortical, através de uma regra de três simples, calculou-se a porcentagem equivalente a cada tipo de osso. Para o cálculo da asa do ílio, verificou-se por meio da observação de pixels que a quantidade de osso cortical é aproximadamente 75\% da área de uma coroa circular. Diante disso, fez-se o cálculo da área da coroa circular considerando somente 75\% desta (Figura 2D).

Através das imagens fornecidas pela tomografia computadorizada, mensurou-se o diâmetro de cada enxerto em três locais diferentes (próximo as duas extremidades e no centro). Em cada local, a espessura foi mensurada em duas direções: de 0 a $180^{\circ}$ e de 90 a $2700^{\circ}$ e sua média obtida.

Após o período de 90 dias ( \pm 5 dias) de congelamento, cada segmento ósseo foi submetido ao ensaio biomecânico na máquina EMIC com capacidade de compressão/flexão de até 100kN e velocidade de $10 \mathrm{~mm} /$ minuto. Para isso, seis horas antes do ensaio, os segmentos foram retirados do freezer e submersos em solução de $\mathrm{NaCl} \mathrm{0,9 \%} \mathrm{para} \mathrm{reidratação.} \mathrm{Após} \mathrm{esse} \mathrm{procedimento,} \mathrm{cada}$ implante foi posicionado perpendicularmente à base da máquina para sofrer força compressiva até a ruptura. O momento da ruptura foi considerado como o valor da carga máxima registrada imediatamente antes do momento em que a amostra falhava em resistir à pressão exercida pela máquina. Tal momento também era observado por um pico máximo no gráfico seguido de um declínio.

Para análise estatística da resistência biomecânica e percentual de osso esponjoso foi utilizada a análise de variância ANOVA e o teste de médias de Scott-Knott com $p<0,05$.

\section{Resultados}

A média do diâmetro das extremidades e no centro dos enxertos foi, respectivamente, de 0,73 e 0,78 cm no grupo A; 0,59 e 0,57 cm no grupo Co; 0,38 e 0,38 cm no grupo C e 0,86 e 0,86 cm no grupo T. O comprimento das $4^{\text {as }}$ vértebras coccígeas variaram de 0,81 a 1,22 cm 
A média de força necessária para produzir ruptura nos segmentos ósseos foi maior no grupo $\mathrm{T}(5979,58 \pm 1605,98 \mathrm{~N})$, seguida do grupo A $(748,51 \pm 352,17 \mathrm{~N})$, grupo Co $(632,31 \pm 215,22 \mathrm{~N})$ e grupo C $(565,35 \pm 272,95 \mathrm{~N})$.

O grupo T, fragmento da tíbia, utilizado como controle, constituído predominantemente por osso cortical, apresentou resistência estatisticamente superior aos demais segmentos. Dentre os três enxertos estudados, não houve diferença quanto a resistência à compressão axial, mas sim em relação a quantidade de osso esponjoso. O segmento de asa do ílio apresentou 69\% de sua estrutura composta por osso esponjoso, enquanto as coccígeas $42 \%$ e costelas $26 \%$.

\section{Discussão}

Um dos cuidados a ser observado na escolha de um enxerto ósseo de segmento total, é o seu diâmetro, pois se espera que seja próximo ao do osso hospedeiro, promovendo aposição quase completa (Millis \& Martinez, 2007). Tal medida foi tomada em três locais diferentes, porque se observou que, especialmente, a vértebra coccígea não apresentava espessura uniforme ao longo do seu comprimento, sendo ligeiramente mais fina no centro e mais larga nas extremidades. Diante dos valores encontrados, pode-se considerá-la, sobre o ponto de vista estrutural, adequada para substituição de segmento ósseo total na tíbia, pois o diâmetro de sua extremidade aproximou-se de $70 \%$ da espessura tibial.

Paralelamente, durante esse estudo, os autores também dissecaram o rádio ea ulna e observaram que ambos são compatíveis com o diâmetro da vértebra coccígea autóloga. A aposição foi próxima de $100 \%$ entre as extremidades ósseas, sugerindo serem locais potencialmente aptos a receberem a enxertia de tal vértebra.

A autoenxertia de vértebras coccígeas vascularizadas (8a, 9a ou $10^{\circ}$ vértebra) já foi descrita com sucesso em defeitos tibiais criados em cães. Entretanto, quando transferido sem anastomose vascular, não houve união óssea (Yeh et al., 1991). Esse resultado sugere que de fato a revascularização imediata favorece a incorporação do enxerto, mas a estabilidade e contato ósseo são fundamentais. O fracasso do tratamento acima citado, foi atribuído pelos autores, ao diâmetro reduzido do enxerto transferido em relação a diáfise da tíbia, além da falta de fixação rígida. O não cumprimento dessas duas condições associada a falta de vascularização imediata, determinou o fracasso da enxertia óssea. Nesse sentido, o trabalho aqui apresentado, sugere a auto enxertia da $4^{\mathrm{a}}$ e $5^{\mathrm{a}}$ coccígeas, as quais apresentam diâmetro maior, aumentando a superfície de contato entre os fragmentos.

Em defeitos mandibulares o emprego das vértebras coccígeas também foi relatado com sucesso. Yeh \& Hou (1994), preencheram a falha mandibular de um cão com o enxerto autógeno vascularizado da 8 a vértebra coccígea. Consideraram o sítio doador de baixa morbidade quando comparado aos outros locais de coleta, mas salientam que o comprimento desse enxerto élimitado. De fato isso foi observado nas coccígeas aqui estudadas, entretanto, considera-se a possibilidade da utilização de vértebras associadas em conjunto, desde que se efetue a correta curetagem do disco intervertebral, evitando a interferência na consolidação entre esses implantes.

De forma semelhante, Aguiar et al. (2007) também reconstruíram a mandíbula de um felino acometido por perda óssea, através da autoenxertia da 14a vértebra coccígea associada a gordura abdominal e imobilização com pinos de Steinmann. Doze meses após a reconstrução mandibular, os exames radiográficos revelaram união óssea completa.

Com relação a costela, observou-se nesse trabalho, que além de curva, sua espessura é delgada, fator que impede a mesma de ser utilizada como autoenxerto de segmento total de osso longo. Contrariamente, a asa do ílio ofereceu espessura compatível com a desejada, entretanto, como uma de suas extremidades é curva, deve-se secciona-la para torná-la plana, para permitir a aposição com o osso hospedeiro e isso deixa seu comprimento limitado. Tanto as costelas quanto a asa do ílio, adequam-se melhor em defeitos mandibulares (Lunardi et al., 2001; Braga-Silva et al., 2005; Gomes, 2008; El-Daharawy et al., 2010), fendas alveolares (Mendonça et al., 2011) e rinoplastias (Santos Júnior et al., 2008).

A análise das propriedades mecânicas dos enxertos corticoesponjosos é recomendada, pois uma vez transplantados, são submetidos, principalmente, a esforços de compressão. Dessa forma, o teste de compressão axial é o mais indicado para testar resistência de um enxerto ósseo (Castania, 2002). 
Os valores dos testes biomecânicos foram analisados estatisticamente, tanto com relação a força de compressão entre os grupos, quanto com relação a resistência dos implantes por milímetro de osso. Em ambas as análises, não houve diferença estatística entre os grupos da asa do ílio, coccígea e costela, mas sim da tíbia. Contudo, o grupo da tíbia proposto nesse trabalho teve a função de grupo controle, informando a resistência original do local receptor do enxerto. Dessa forma, sua superioridade biomecânica com relação aos enxertos corticoesponjosos era esperada, visto apresentar estrutura predominantemente cortical. Os ossos corticais apresentam apenas 5 a 30\% de porosidade, ao contrário do osso esponjoso que pode chegar a 90\% (Hulse \& Hyman, 2007). Essa característica confere, ao osso cortical, maior resistência à deformação e como resultado suporta mais carga que o osso esponjoso antes de ocorrer a fratura (Momin et al., 2013).

Ainda embasado nas características de um bom segmento de enxerto, atenta-se para que não só a resistência é fato importante. Espera-se sim, que um enxerto corticoesponjoso possua uma quantidade de osso cortical capaz de garantir suporte estrutural, mas que haja osso esponjoso suficiente para fornecer células osteogênicas (Millis \& Martinez, 2007).

A proporção elevada de osso esponjoso encontrada na vértebra coccígea revela sua grande capacidade osteogênica, a qual foi confirmada por Mcduffee \& Anderson (2003), que pesquisaram o potencial osteogênico, através de cultura celular in vitro, de cinco sítios doadores em equinos: metáfise da tíbia, esterno, tuberosidade coxal, $4^{a}$ vértebra coccígea e periósteo da diáfise tibial. Os melhores rendimentos celulares foram da tuberosidade coxal, periósteo e a 4 a vértebra coccígea.

Cabe ressaltar a importância dos autoenxertos ósseos, por possuírem, potencialmente, os principais fatores favoráveis à incorporação: osteoindução, osteocondução, osteogênese eausência de reação imunológica (Mendonça et al., 2011). Dessa forma, utilizando-se das coccígeas, tais propriedades são mantidas e os pacientes beneficiados com o tratamento de menor morbidade e melhores condições de sucesso.

Diante das características analisadas, cabe ressaltar que a vértebra coccígea reuniu atributos inerentes aos enxertos corticoesponjosos de segmento ósseo total. Sua espessura e seu formato reto e cilíndrico permitem adequada aposição óssea entre os fragmentos; e sua resistência biomecânica associada ao elevado percentual de osso esponjoso, lhe confere suporte estrutural e grande poder osteogênico.

\section{Conclusão}

Os enxertos da costela, asa do ílio e coccígea não diferem estatisticamente quanto a resistência à compressão axial. Entretanto, a vértebra coccígea apresenta maior quantidade de osso esponjoso do que as costelas e conformação cilíndrica melhor ajustável aos ossos longos do que a asa do ílio, tornando-se uma boa opção para substituição de segmento ósseo total de ossos longos.

\section{Agradecimentos}

Ao professor Carlos Jesus Haygert pela disponibilidade na realização do exame de tomografia computadorizada.

\section{Referências}

Aguiar, E. S. V., Schossler, J. E. W., Caríssimi, A. S., \& Soares, D. G. (2007). Reconstrução mandibular para reparo da perda de tecido ósseo em felino mediante o emprego de enxerto ósseo e adiposo autógenos e pino de Steinmann. Acta Scientiae Veterinariae, 35, 348-349.

Bauer, T. W., \& Muschler, G. F. (2000). Bone graft materials: an overview of the basic science. Clinical Orthopaedics and Related Research, 371,10-27. http://dx.doi.org/10.1097/00003086-200002000-00003. PMid:10693546.

Braga-Silva, J., Martins, P. D. E., Román, J. A., \& Gehlen, D. (2005). Reconstrução do segmento ósseo mandibular: comportamento dos implantes ósseo-integrados nos retalhos vascularizados de crista ilíaca e fíbula. Revista Brasileira de Cirurgia Plástica, 20, 176-181.

Castania, V. A. (2002). Enxerto córtico-esponjoso homógeno processado quimicamente e esterilizado em óxido de etileno em cães (Dissertação de mestrado). Universidade de São Paulo, Ribeirão Preto.

Denny, H. R., \& Butterworth, S. J. (2006). Enxertos ósseos. In H. R. Denny, \& S. J. Butterworth (Eds.), Cirurgia ortopédica em cães e gatos (4a ed., pp. 14-18). São Paulo: Roca.

El-Daharawy, M. H., Shekidef, M. H., Ahmed, I. H., \&Zayed, M. (2010). The effect of immobilization on reconstruction of mandibular defect using free iliac crest bone graft in dogs. Nature and Science, 8, 52-58. 
Gomes, C. (2008). Avaliação da cicatrização óssea em falha mandibular com autoenxerto ósseo associado a suspensão celular de medula óssea autógena: estudo experimental (Dissertação de mestrado). Universidade Federal do Rio Grande do Sul, Porto Alegre.

Hulse, D., \& Hyman, B. (2007). Biomecânica e biologia das fraturas. In D. Slatter (Ed.), Manual de cirurgia de pequenos animais (3a ed., pp. 1785-1792). São Paulo: Manole.

Lunardi, D. V., Fava, A. S., Martins, R. H., Homem, M. G. N., Rapoport, A., \& Carvalho, M. B. (2001). Tratamento cirúrgico do ameloblastoma com reconstrução de mandíbula com enxerto de crista ilíaca não vascularizado - estudo de sete casos. Revista do Colégio Brasileiro de Cirurgiões, 28(1), 9-12. http://dx.doi.org/10.1590/ S0100-69912001000100003.

McDuffee, L. A., \& Anderson, G. I. (2003). In vitro comparison of equine cancellous bone graft donor sites and tibial periosteum as sources of viable osteoprogenitors. Veterinary Surgery, 32(5), 455-463. http://dx.doi. org/10.1053/jvet.2003.50060. PMid:14569574.

Mendonça, J. C. G., Lima, C. M. C., \& Terra, G. A. P. (2011). Uso de enxerto ósseo autógeno de crista ilíaca na reconstrução de fenda alveolar em paciente fissurada: relato de caso. Revista Brasileira de Cirurgia Craniomaxilofacial, 14, 162-165.

Millis, D. L., \& Martinez, S.A. (2007). Enxertos ósseos. In D. Slatter (Ed.), Manual de cirurgia de pequenos animais (3a ed., pp. 1875-1891). São Paulo: Manole.

Momin, M. A., Kurabayashi, T., \& Yosue, T. (2013). Quantitative and morphological evaluation of cancellous and cortical bone of the mandible by CT. OMICS Journal of Radiology, 3, 1-5.

Piermattei Filho, D. L. G. L., \& Decamp, C. E. (2009). Enxertos ósseos. In D. L. G. L. Piermattei Filho, \& C. E. Decamp (Eds.), Ortopedia e tratamento de fraturas de pequenos animais (4.ed., pp. 180-188). São Paulo: Manole.

Santos Júnior, E. B., Contesini, E. A., Beheregaray, W. K., Schiochet, F., Pöppl, A., Moura, L., Pelizari, M., \& Kroth, E. (2008). Rinoplastia experimental com enxerto autógeno de costela em cães. Arquivo Brasileiro de Medicina Veterinária e Zootecnia, 60(2), 346-352. http://dx.doi.org/10.1590/S0102-09352008000200011.

Serafini, G. M. C., Müller, D. C. M., \& Pippi, N. L. (2016). Atualidades em enxertia óssea. Revista Científica de Medicina Veterinária Pequenos Animais e Animais de Estimação, 14, 102-105.

Stevenson, S. (1996). Enxertadura óssea. In: M. J. Bojrab (Ed.), Técnicas atuais em cirurgia de pequenos animais (3a ed., pp. 758-819). São Paulo: Roca.

Yeh, L. S., \& Hou, S. M. (1994). Repair of a mandibular defect with a free vascularized coccygeal vertebra transfer in a dog. Veterinary Surgery, 23(4), 281-285. http://dx.doi.org/10.1111/j.1532-950X.1994.tb00483.x. PMid:8091631.

Yeh, L. S., Hou, S. M., \& Lin, A. C. (1991). Vascularized autogenous canine coccygeal bone transfer. Microsurgery, 12(5), 326-331. http://dx.doi.org/10.1002/micr.1920120503. PMid:1770861. 